\title{
Aspectos da pesquisa sobre tipologia textual
}

\author{
Aspects of research on text typology
}

\section{Luiz Carlos Travaglia Universidade Federal de Uberlândia}

\section{Resumo}

Este artigo chama a atenção dos pesquisadores sobre tipologia textual, na área da Linguística Textual, sobre aspectos que são importantes para que estas pesquisas gerem conclusões e generalizações mais confiáveis. Os pontos comentados são: a) a necessidade de uma teoria tipológica geral de textos que inclusive determine se as categorias de texto são todas da mesma natureza. $\mathrm{O}$ autor propóe uma teoria geral; b) a necessidade de estudos mais horizontalizados ou amplos que estabeleçam campos de pesquisa e de estudos mais verticalizados, que aprofundam o conhecimento de pontos específicos; c) os aspectos metodológicos para superar problemas no levantamento das categorias de texto existentes em uma sociedade e cultura, em suas diversas comunidades discursivas e esferas de ação social; d) a questão dos parâmetros e critérios para considerar uma categoria de texto como sendo uma categoria e se ela é de determinada natureza; e) a questão dos critérios e parâmetros para a caracterização das categorias de texto; f) a necessidade de estudar as diversas relações de diferentes tipos que podem ocorrer entre as categorias de texto (de diferentes naturezas), tanto em sua composição quanto em seu funcionamento sociodiscursivo; e g) a atenção que merece a questão teminológica.

\section{Palavras-chave}

Tipologia textual, Pesquisa, Tipos, Subtipos, Gêneros, Espécies. 


\section{Abstract}

This paper focuses on important aspects of the research on textual typology, in the field of Textual Linguistics, in order to provide more reliable conclusions and generalizations to researchers. The examined points are: a) the need for a general typological theory of texts that even determine if the categories of texts are all of the same nature; for that, the author proposes a general theory; b) the need for more horizontal or extensive studies, which establish fields of research, and also the need for more vertical studies, which deepen the knowledge of specific aspects; c) methodological aspects to overcome problems in surveying categories of texts that exist in a given society and in its culture, in its various discursive communities and spheres of social action; d) parameters and criteria which establish a category of text as a category itself, and also determine its nature; e) parameters and criteria that characterize the categories of text; f) the need for studying the different types of relations that can occur between the categories of texts (of different natures), both in their composition, and in their sociodiscursive function; and $\mathrm{g}$ ) the attention required by the terminological issue.

\section{Keywords}

Textual tipology, Research, Types, Subtypes, Textual genres, Species. 


\section{Introdução}

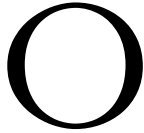

objetivo neste artigo é, com base tanto em nossa experiência de pesquisa nesta área quanto no que temos lido sobre o assunto e observado na experiência de outros pesquisadores, fazer algumas considerações relativas à pesquisa sobre tipologia textual, ressaltando pontos que consideramos importantes para essa área de pesquisa na busca de resultados pertinentes para o conhecimento do funcionamento da língua no nível textual e para o domínio das habilidades que se configuram importantes para o falante no uso das categorias de texto.

Como se pode perceber a pesquisa nessa área tanto pode se concentrar na produção de conhecimento sobre as categorias de textos em si, para a descrição e explicação de sua constituição e funcionamento, quanto no ensino e aprendizagem dessas categorias pelos falantes em situações formais ou informais de ensino. Este artigo se volta mais especificamente para o primeiro aspecto.

Quando falamos em tipologia textual, não estamos nos referindo a tipos de texto, no sentido estrito com que vários autores têm usado este termo em oposição, por exemplo, a gêneros e espécies, mas num sentido geral. Assim, estamos falando da taxionomia dos textos, sua classificação, atribuindo-os a alguma categoria de texto como as definimos em Travaglia (2004, 2007a, 2007b, 2009) e retomamos mais adiante neste texto.

O problema terminológico é um dos problemas de pesquisa que abordamos, mas, para podermos falar com uma linha base de referência e comparação, vamos retomar a seguir alguns termos e indicar o sentido com que os temos usado em nossa pesquisa e estudos e publicações mais recentes. São eles: categorias de texto, tipelementos (tipo / subtipo, gênero e espécie).

Para nós, o termo categoria de texto ${ }^{1}$ designa qualquer classificação que uma sociedade e cultura dê a um texto, tipologizando-o, e a categoria de texto 
é um conjunto de textos com características comuns, ou seja, uma classe de textos que têm uma dada caracterização, constituída por um conjunto de características comuns em termos de conteúdo, estrutura composicional, objetivos e funçōes sócio-comunicativas, características da superfície lingüística, condições de produção, etc., mas distintas das características de outras categorias de texto, o que permite diferenciá-las (cf. TRAVAGLIA, 2004). ${ }^{2}$ São exemplos de categorias de texto em nossa sociedade e cultura brasileiras: descrição, dissertação, injunção, narração, texto argumentativo "stricto sensu", texto preditivo, romance, novela, conto, fábula, parábola, caso, ata, notícia, mito, lenda, certidão, requerimento, procuração, atestado, denúncia, ofício, carta, soneto, haikai, ditirambo, ode, acróstico, epitalâmio, prece, tragédia, comédia, farsa, piada, tese, artigo, etc. (TRAVAGLIA, 2007a, p. 40).

Consideramos que as categorias de textos podem ser de naturezas distintas, que chamamos de "tipelementos" (cf. TRAVAGLIA, 2001; [2003]/2007; 2009) que são, então, classes de categorias de texto de uma dada natureza. Até o momento identificamos quatro naturezas distintas a que uma categoria de texto pode pertencer: o tipo, o subtipo, o gênero e a espécie.

O tipo pode ser identificado e caracterizado por instaurar um modo de interação, uma maneira de interlocução (cf. TRAVAGLIA, 1991, cap. 2), segundo perspectivas que podem variar constituindo critérios para o estabelecimento de tipologias diferentes (cf. TRAVAGLIA, 2001, [2003]/2007, p. 101-104). Alguns tipos que podemos citar, divididos em oito tipologias, ${ }^{3}$ são:

a) texto descritivo, dissertativo, injuntivo, narrativo;

b) texto argumentativo "stricto sensu" e argumentativo não "stricto sensu";

c) texto preditivo e não preditivo;

d) texto do mundo comentado e do mundo narrado;

e) texto lírico, épico / narrativo e dramático;

f) texto humorístico e não humorístico;

g) texto literário e não literário;

h) texto ficcional e factual. 
O subtipo ${ }^{4}$ se caracteriza e pode ser identificado por ser uma categoria de texto que, na verdade, é um tipo, mas não um tipo independente, e sim uma variedade de um determinado tipo caracterizado por uma perspectiva única em que os subtipos se encaixam. Os subtipos se distinguem por alguns fatores e traços que, pelo que observamos até o momento, não são sempre os mesmos. Para o tipo dissertativo, encontramos a existência de dois subtipos: o expositivo e o explicativo. Para o tipo injuntivo, observamos a existência de seis subtipos: a ordem, o pedido, a súplica, o conselho, a prescrição e a optação ou volição.

$\mathrm{O}$ gênero se caracteriza por exercer uma função sociocomunicativa específica. Essas nem sempre são fáceis de explicitar. O gênero é um instrumento para a ação linguística na sociedade em situações tipificadas. Alguns exemplos de gêneros são: romance, novela, conto, fábula, apólogo, parábola, mito, lenda, caso, biografia, piada, notícia, certidão, atestado, mandado, procuração, artigo, tese, dissertação, resenha, tragédia, comédia, drama, farsa, auto, esquete, edital, convite, prece, oratório (sermão, discurso, etc.), didático, contrato, correspondência, denúncia, boletim de ocorrência, etc.

A espécie se define e se caracteriza apenas "por aspectos formais de estrutura (inclusive superestrutura) e da superfície lingüística e/ou por aspectos de conteúdo." (cf. TRAVAGLIA, 2001, [2003]/2007, p. 104-106). Podemos dar como exemplos de espécies:

a) história e não história (espécies do tipo narrativo);

b) textos em prosa e textos em verso;

c) históricos, psicológicos, regionalistas, indianistas, fantásticos, de ficção científica, de capa e espada, policiais, eróticos, autobiográficos etc. (para romances ou contos);

d) carta, telegrama, ofício, memorando, bilhete, etc. (espécies do gênero correspondência ou epistolar, conforme alguns preferem dizer);

e) epitalâmio, ditirambo, elegia, écloga, idílio, acróstico, soneto, balada, haicai (espécies do tipo lírico, gênero poema).

As espécies de romances e contos referidas em c, por exemplo, são definidas pelo conteúdo, enquanto o soneto e o haicai, espécies de poemas líricos, são definidos pela forma: a) o soneto se caracteriza por ser composto por quatorze versos distribuídos em dois quartetos e dois tercetos nesta ordem e mais alguns aspectos de rima e metro, não obrigatórios; b) o haicai se caracteriza pela concisão 
tendo apenas dezessete sílabas distribuídas em três versos: cinco sílabas no primeiro e terceiro versos e sete sílabas no segundo. Atualmente a característica que é mais respeitada do haicai é a concisão e a distribuição em três versos, pois nem sempre se obedece ao número de sílabas em cada verso.

As relações possíveis entre tipos/subtipos, gêneros e espécies (ver mais detalhes em TRAVAGLIA ([2003]/2007) e as relações entre os tipos na composição dos gêneros (ver TRAVAGLIA, 2007b) podem ser assim resumidas:

1) os tipos e espécies compõem os gêneros que são os tipelementos que existem e circulam na sociedade;

2) as espécies podem estar ligadas a tipos (como a história e a não história que são espécies do tipo narrativo) ou a gêneros (como a carta, carta comercial, o ofício, a circular, o memorando, o bilhete, o telegrama, o cartão que são espécies do gênero correspondência);

3) os gêneros podem estar ligados a tipos que os compõem necessariamente (como a tese é necessariamente composta pelo dissertativo como dominante) ou não (como a carta que pode ser composta por descritivo, dissertativo, injuntivo ou narrativo, mas não necessariamente) ou a espécies de tipos (como o romance, o conto, a piada, por exemplo, que são compostos pela espécie história do tipo narrativo) ;

4) quando os tipos compõem os gêneros, eles podem (cf. TRAVAGLIA, 2007b):

a) se cruzar ou fundir: neste caso o gênero apresenta características de dois ou mais tipos simultaneamente, no mesmo espaço textual. É o caso, por exemplo, do "editorial" de jornal que é composto, ao mesmo tempo, necessária e dominantemente pelos tipos dissertativo e argumentativo "stricto sensu"; da piada que, simultaneamente, é composta necessária e dominantemente pelos tipos narrativo e humorístico e do apólogo, fábula e parábola que são compostos pelos tipos narrativo e argumentativo "stricto sensu"em cruzamento ou fusão;

b) se conjugar: neste caso os tipos aparecem lado a lado na composição do gênero, em espaços textuais distintos, não havendo, pois, uma fusão de características no mesmo trecho. Assim, o editorial apresenta trechos descritivos, injuntivos e narrativos ao lado dos trechos dissertativos, geralmente representando argumentos ou 
com outras funções dentro do editorial. ${ }^{5}$ Já o romance geralmente apresenta, além do narrativo, que é obrigatório e dominante, trechos descritivos, dissertativos e injuntivos. Este último mais eventualmente, mas a descrição e a dissertação quase sempre. $\mathrm{Na}$ bula, tem-se os tipos descritivo, dissertativo, injuntivo e narrativo, mas nenhum é dominante. Portanto, quando os tipos se conjugam um deles pode ser dominante ou não. A dominância pode ser necessária (acontece sempre no gênero) ou não (pode acontecer, mas não obrigatoriamente)

c) se intercambiar: neste caso, em uma situação de interação em que se esperava um tipo ou gênero, tendo em vista o modo de interação que se estabelece e que exigiria uma dada categoria de texto, ocorre outra categoria. O produtor do texto lança mão de uma categoria que não é a própria daquele tipo de interação naquela esfera de ação social, para produzir determinados efeitos de sentido.

Estabelecido este referencial básico que será usado neste artigo como um modelo nosso para a constituição de uma tipologia geral de textos e para a organização de estudos tipológicos de texto, gostaríamos de passar a comentar alguns aspectos e questóes da pesquisa sobre tipologia textual que nos parecem pertinentes.

\section{Uma tipologia geral de textos}

A primeira grande questão para a pesquisa sobre tipologia textual parece ser a possibilidade de tal pesquisa, reconhecidamente uma tarefa da Linguística Textual, ${ }^{6}$ conduzir a uma teoria tipológica geral de textos. Em segundo lugar, se a resposta for sim, qual seria o formato dessa teoria?

Em estudos realizados e que nos levaram a escrever Travaglia ([2003]/ 2007), chegamos à conclusão de que é, sim, possível estabelecer uma teoria tipológica geral, mas não em termos da congregação num grande esquema de todas as tipologias estabelecidas por muitos estudos realizados em diferentes áreas e com base em critérios e parâmetros variados, materiais diferentes e com finalidades e objetivos diversos. Não creio ser possível conjugar em um quadro geral classificações estabelecidas por autores e estudos diversos, por exemplo: 
a) Vanoye (1982) que, usando as funções da linguagem, propõe que haveria os seguintes tipos de textos (ou mensagens) de acordo com a função predominante: referencial, expressivo, conativo, fático, metalinguístico e poético;

b) Benveniste (apud GUIMARÃES, 1995, 46): que classifica a enunciação em histórica e discursiva,

c) Simonin-Grumbach (1983): que ampliando Benveniste propõe os seguintes tipos de texto: discurso, história, discurso relatado, textos teóricos e textos poéticos;

d) Weinrich (1968) com sua famosa distinção entre textos do mundo narrado e do mundo comentado;

e) Werlich (1975, apud FÁVERO; KOCH, 1987): descritivo, narrativo, expositivo, argumentativo e instrutivo.

f) Fávero e Koch (1987), que com base inclusive em Werlich (1975) e outros, falam em tipos narrativo, descritivo, expositivo ou explicativo, argumentativo "stricto sensu", injuntivo ou diretivo e preditivo, postos numa única tipologia;

g) Adam (1993): que propõe as sequências narrativa, descritiva, argumentativa explicativa e dialógica, que seriam tipos em nossa proposta;

h) Bronckart (2003): que propóe a existência de quatro arquétipos: discurso interativo, relato interativo, discurso teórico e narração, que passam a tipos linguísticos de textos;

i) Dolz e Schneuwly (2004): ${ }^{7}$ propõem cinco tipos de textos que são comumente referidos como ordens ao listar gêneros que pertenceriam a cada ordem ou tipo. As cinco ordens são: narrar, relatar, argumentar, expor e descrever açóes. O narrar e o relatar são textos narrativos que se distinguiriam (conforme nossa leitura pelos exemplos de gêneros de cada ordem elencados) por serem, respectivamente, narrativas ficcionais ou factuais. $\mathrm{O}$ argumentar é o texto argumentativo stricto sensu; o expor seria o texto dissertativo em geral e a ordem do descrever ações parece-nos que são os textos injuntivos. Essa organização foi feita pelos autores visando o ensino e tem sido muito usada nessa área.

j) a proposta da teoria literária com seus gêneros (lírico, épico ou narrativo e dramático) e as inúmeras espécies desses.

k) etc. 
Seria difícil, e mesmo impossível, conjugar em um único esquema classificatório tipologias como as explicitadas acima. Todavia nos parece ser possível estabelecer uma teoria que crie um quadro geral em que encaixar as inúmeras pesquisas e estudos de elementos mais pontuais, fazendo dessa teoria tipológica geral uma inequívoca necessidade epistemológica. Cremos ter conseguido esboçar um modelo possível para essa teoria geral com o que propusemos em vários textos sobre tipologia textual, mas mais especificamente em Travaglia (2001, [2003]/2007, 2007a, 2007b, 2009, 2012). Essa teoria não se constrói pela conjugação de todas as classificaçôes criadas por estudiosos diversos, sobretudo porque isso seria difícil, e mesmo impossível, considerando que, como já dissemos,

Tais tipologias geralmente são construídas para um objetivo específico de trabalho, utilizando um ou mais critérios classificatórios e levando em conta a natureza do material textual que se tem em mãos para estudo ou para aplicaçóes práticas como as de ensino / aprendizagem de produção / compreensão de textos. (TRAVAGLIA, [2003]/2007, p. 97)

e também são resultado de abordagens diversas pelas disciplinas que as constroem: literária, linguística, antropológica, psicológica, pedagógica, entre outras.

A teoria tipológica geral, todavia, é possível, como dissemos em Travaglia ([2003]/2007) em termos da construção de um modelo que explicite:

a) o que é comum a todas as tipologias existentes ou a serem propostas;

b) que elementos podem e / ou devem entrar na constituição de uma tipologia e que relações podem manter entre si;

c) que aspectos têm de ser levados em conta para construir uma tipologia.

Toda teoria tipológica de textos deve dizer:

a) os parâmetros e critérios utilizados para propor a tipologia;

b) os objetivos com que foi construída e o material textual que serviu de corpus ou material empírico para sua proposição;

c) os elementos / categorias que compõem a tipologia e se são da mesma natureza ou não; 
d) quais as relações possíveis entre esses elementos ou categorias;

e) como as categorias presentes na tipologia são caracterizadas, ou seja, quais os parâmetros e critérios usados na caracterização; e, finalmente,

g) como é o funcionamento discursivo e social das categorias propostas e como é a rede social que interliga as categorias presentes na tipologia (cf. BAZERMAN, 2005).

Em nossos estudos propusemos uma teoria tipológica geral que aparece resumida na introdução e que propóe basicamente:

a) que existem categorias de textos (o que parece ser consensual a todos que se propõem a falar de tipologia de textos, mesmo que a terminologia seja outra. Isso seria um pressuposto de partida), ou seja, classes de textos reconhecíveis em uma sociedade e cultura e que as categorias de texto podem ser levantadas em cada sociedade e cultura como um todo, mas também agrupadas por loci em que se estabelecem e são produzidas e que seriam basicamente de dois tipos: as comunidades discursivas e as esferas de ação social (cf. TRAVAGLIA, 2012);

b) que essas categorias são distinguíveis por meio de suas características dadas por parâmetros e critérios diversos, ligados a conteúdo temático; estrutura composicional; características da superfície linguística ou estilo, conforme termo de Bakhtin (1992) no capítulo "Os gêneros do discurso" (p. 277-325); objetivos e funções sociocomunicativas em seu funcionamento sociodiscursivo, talvez como diz Marcuschi (2002, p. 24) a "ação prática" realizada no caso dos gêneros; aspectos ligados a condiçôes de produção além de suporte típico em alguns casos. Portanto, é possível caracterizar essas categorias de texto (cf. TRAVAGLIA, 2007a);

c) que as categorias de texto não são todas da mesma natureza e que, portanto, as diferentes naturezas devem ser identificadas sob pena de criarmos confusões e problemas epistemológicos desnecessários no estudo, pesquisa e modelização teórica resultante. Como já dito, em nosso estudo encontramos quatro naturezas distintas de categorias de texto a que demos o nome geral de "tipelementos" e que seriam: tipo, subtipo, gênero e espécie (cf. TRAVAGLIA, [2003]/2007, 2009); e 
d) que há entre os tipelementos relações diversas que são regulares no seu modo de acontecer na língua, o que vai facilitar o estudo tipológico (cf. TRAVAGLIA, [2003]/2007, 2007b, para ver as relações propostas). Elas foram resumidas na introdução. Essas relações têm a ver, em primeiro lugar, com as vinculações possíveis entre tipos / subtipos gêneros e espécies (ver na introdução os itens 2 e 3 quando se fala dessas relações) e, em segundo lugar, com a composição de gêneros por tipos / subtipos e espécies (ver na introdução os itens 1 e 4, na parte que fala das relações).

Ainda sobre as relações entre os tipelementos, registradas em d, é preciso registrar que, em terceiro lugar, observa-se que os gêneros têm entre si relações que podem ser vistas como um tipo de "intertextualidade" (conforme propóe BAZERMAN, 2005). Tais relações podem ter uma motivação de causalidade, como é o caso dos gêneros que provocam o surgimento de outros dentro de um "locus" de estabelecimento e produção de gêneros. Assim, por exemplo, no campo da educação, leis levam escolas a produzir currículos ou planos pedagógicos. Estes levam professores a produzir fichas de disciplinas e depois de acordo com estas a produzir planos de curso que, por sua vez, levam aos planos de aula, aos diários de classe, às avaliações, e assim por diante. Os planos de curso podem levar alunos a produzir monografias, trabalhos, fichas de leitura, resenhas, resumos, exposições orais, debates, etc. Essa espécie de intertextualidade pode ter a ver não com causalidade de produção entre gêneros, mas uma espécie de relação que leva um gênero em sua produção e validade social a ter uma relação outra com outros textos de outros gêneros. É caso do formulário do imposto de renda, ${ }^{8}$ cuja produção / preenchimento só ocorre por meio de uma inter-relação com textos outros de outros gêneros, por exemplo: a) as leis, resoluçóes, portarias vindas da Receita Federal sobre a ação de cidadão de pagamento de impostos; b) recibos e notas fiscais de despesas diversas que podem ou não funcionar como abatimento do montante da renda sobre o qual será calculado o imposto ou como abatimento direto no imposto a ser pago; c) informes de rendimentos diversos; d) informes bancários sobre depósitos e rendimentos de aplicações isentas de tributação (como caderneta de poupança) ou tributadas exclusivamente na fonte; e) outras declarações feitas pelo contribuinte durante o correr do ano base como carnê-leão, de atividade rural, de ganhos de capital, etc.; f) decisões judiciais determinando pagamento de pensão a dependentes; e g) comprovantes de 
dívidas e ônus reais sob o encargo do declarante e muitos outros documentos (de gêneros diferentes) conforme a complexidade da vida econômica de cada contribuinte. Essas relações todas, de diferentes naturezas, podem ser objeto de pesquisas em projetos específicos.

Acreditamos que o que propusemos até agora seja um primeiro passo para a construção dessa teoria tipológica geral dos textos, ou um primeiro passo para se abrir a discussão dessa questão de forma mais concreta para aqueles que se disponham a fazer outras propostas. O que nos parece impossível é continuar fazendo pesquisa sobre tipologia textual, propondo tipologias, caracterizando tipos ou gêneros ou qualquer outro elemento (conforme a terminologia adotada) sem ter uma teoria geral e um quadro geral em que cada elemento estudado se encaixe, pois fazer isso é permitir um equívoco epistemológico que pode prejudicar a compreensão do fato ou fenômeno da existência das categorias de texto e seu funcionamento. Em Travaglia ([2003]/2007), lembramos que, por exemplo, não considerar o fato de que gêneros (em nossa definição como um dos tipelementos ou naturezas das categorias de texto) são compostos por tipos / subtipos e espécies pode levar o pesquisador a apresentar como características exclusivas de um gênero o que é comum a vários gêneros compostos pelo mesmo tipo. Obviamente, como dissemos em Travaglia (2007a), ser composto por um certo tipo é uma característica do gênero, mas é preciso saber que é uma característica comum a outros gêneros e ir além para saber o que é específico do gênero, distinguindo-o de todos os demais. Apraz-me sempre lembrar para ilustrar esse ponto, o trabalho de caracterização e distinção da fábula, parábola e apólogo, feita por Arantes (2006). Os três gêneros são muito próximos porque: a) são compostos pelos tipos narrativo (da espécie história) e argumentativo "stricto sensu" em fusão, portanto com as características dos dois num dado espaço textual; b) como gêneros, têm um objetivo e função sociopedagógica comum ${ }^{9}$ (ensinar como agir em determinadas circunstâncias da vida) e só vão se distinguir por certos detalhes da realização da superestrutura da narração da espécie história e da forma de argumentar no que respeita a alguns aspectos, por exemplo, o tipo de argumento utilizado.

A pesquisa tipológica de textos pode ter focos distintos e ser feita por razões diversas, mas se beneficiará, sem dúvida, de uma teoria tipológica geral, para avançar de maneira organizada dentro de um modelo. Essa nos parece uma lacuna na maioria das pesquisas tipológicas de texto ${ }^{10}$ e que temos buscado 
suprir. Cumpre ainda ressaltar que uma teoria tipológica geral organiza sobremaneira o ensino ligado a categorias de texto, evitando uma selva intrincada e um tanto sem caminhos claros de teorias diversas e com problemas terminológicos, que geralmente o professor tem enfrentado, começando pelo que se considera como tipo, gênero, etc. e outros problemas criados por não se distinguir e correlacionar as diferentes naturezas das categorias de texto.

\section{O levantamento das categorias existentes em uma sociedade e cultura}

Qualquer pesquisa tipológica de textos, uma vez escolhido um referencial teórico que forneça os instrumentos de análise, implica, sem dúvida, o levantamento ou constatação da existência de uma ou várias categorias de texto, seja tipo, subtipo, gênero ou espécie. A própria aceitação de que as categorias podem ter naturezas diferentes (tipelementos), vai fazer com que a pesquisa se realize de modo diverso. De qualquer maneira, parece-nos que o levantamento das categorias de texto existentes na sociedade e cultura brasileiras tem de ser uma das tarefas da pesquisa sobre tipologia textual. Esse levantamento nos parece suscitar o principal problema metodológico desse tipo de pesquisa.

O número de tipos, subtipos e espécies parece não ser muito grande, mas sempre se afirmou que o de gêneros é praticamente ilimitado, o que é, naturalmente, uma hipérbole para afirmar que são muito numerosos. Assim, a maior tarefa da pesquisa tipológica é levantar os gêneros, pois o levantamento dos tipos / subtipos e espécies nos parece ser decorrente da sua identificação na composição dos gêneros levantados, conforme proposto. Como levantar os gêneros para estudo?

Evidentemente muitos gêneros têm circulação ampla na sociedade e o acesso a eles para estudo é relativamente fácil, bem como a obtenção de vários exemplares para a constituição de um corpus razoável e pertinente para os fins gerais e específicos da pesquisa, o que talvez explique o fato de muitos deles serem objeto de vários estudos. É o caso dos gêneros da comunidade artístico-literária (romances, contos, novelas, crônicas, epopéias, poemas heróicos, poemas de espécies diversas - soneto, haicai, balada, epitalâmio, écloga, vilancete, vila real, ditirambo, etc. - fábula, tragédia, comédia, auto, etc.), que produz textos para serem apresentados aos outros, com objetivos como o entretenimento, a fruição estética ou mesmo outros objetivos como os de defesa e / ou divulgação de 
posturas, ideologias, etc., o que se chama de literatura engajada. $\mathrm{O}$ mesmo acontece com os gêneros jornalísticos publicados nos jornais e revistas (notícias, reportagens, subretrancas, editoriais, cartas ao leitor, chamada, entrevista, perfil, texto legenda, etc.) ${ }^{11}$ com gêneros acadêmicos, como resumos, resenhas, monografias, dissertaçóes, teses, artigos científicos, ensaios, etc. e com gêneros diversos do convívio social e usados em muitas comunidades discursivas como os convites, e as cartas (das mais diferentes espécies), declarações, atestados, anúncios, etc.

Todavia, a grande maioria dos gêneros não está disponível para todos, e eles permanecem "fechados" nas comunidades que os produzem. Isso cria dificuldades para a pesquisa sobre esses gêneros, pois, como dissemos em Travaglia (2011),

Com muita frequência, uma das grandes dificuldades da pesquisa de gêneros junto a comunidades discursivas é o acesso à vivência das mesmas e participação de suas rotinas, o que permite não só levantar os gêneros, mas também perceber a relação entre eles, seu possível encadeamento em termos de sucessão causal ou não, hierarquização, condicionamentos de aspectos diversos, etc. Essas dificuldades podem ser fruto de limitações de tempo e disponibilidade do pesquisador para participar das rotinas da comunidade, mas também, muito frequentemente, vêm de fatores como uma certa reserva dos membros das comunidades em relação aos propósitos do pesquisador, o receio de interferência na rotina da comunidade, os sigilos profissionais ou de outra natureza (que obstaculizam a consulta a textos para a análise) e mesmo pouca disponibilidade de tempo dos membros das comunidades. Daí a relevância de comunidades e membros da mesma que entendem a importância da pesquisa e cooperam efetivamente" (TRAVAGLIA, 2011, p. 2).

Assim, por exemplo, Silva (2007), pesquisando os gêneros da comunidade jornalística em seu mestrado, teve de ater-se aos gêneros presentes nos jornais e revistas, porque não obteve autorização dos jornais para participar da vida da comunidade jornalística, com o objetivo de levantar e caracterizar os gêneros que são usados por eles na comunicação interna e interpares e que não são publicados nos veículos jornalísticos. Já Cardoso (2010) teve que superar, para a realização de seu estudo, o temor dos dirigentes de uma firma de Engenharia Civil de que 
documentos de sua empresa pudessem ser espionados por outras firmas. Essa mesma pesquisadora buscou estudar os gêneros utilizados pelos Correios e a resposta que obteve foi a de que tiveram aborrecimentos em relação a pesquisas dessa natureza e que por isso estavam suspensas... A solicitação por mim de cópias de um gênero da área da agrimensura a um profissional, contactado quando ele fazia cópias do texto em uma firma de reprografia, nunca foi atendida, apesar de todas as explicações do objetivo e mesmo a apresentação de documentos para evidenciar que eu era realmente um professor universitário e que estava fazendo pesquisa sobre gêneros de texto. Amigos da área médica, a quem solicitamos auxílio na pesquisa dos gêneros utilizados na área da saúde, se dispuseram a ajudar, mas não o fizeram até o momento em que escrevemos este texto, por falta de tempo de estar com o pesquisador para o levantamento dos gêneros e de exemplares para estudo.

Ou seja, por razões diversas, a pesquisa, principalmente dos gêneros, como os definimos, para seu levantamento, caracterização e verificação de seu funcionamento social, não é muito fácil de ser realizada, a não ser que o pesquisador seja membro da comunidade que pesquisa. Essa tem sido a via mais comum para afastar os obstáculos a que nos referimos, mas o que fazer quando o pesquisador não pertence à comunidade? Nesses casos, têm valido as amizades, apresentações, mas, mesmo assim, isso nem sempre funciona. Essa é uma questão metodológica importante a ser considerada pelo pesquisador da área, pois pode levar ao fracasso de um projeto.

Podemos dizer que apresentações e referências abriram-me as portas para a pesquisa que resultou no levantamento dos gêneros militares que apresentei em Travaglia (2011), todavia não foi possível um acesso pessoal mais amplo aos documentos para levantar os gêneros e nem fazer cópias dos exemplares, sem qualquer restrição. O convívio com a comunidade, todavia, levou alguns de seus membros a colaborar, permitindo cópias de exemplares que lhes dizia respeito pessoalmente e a cooperar com o registro de gêneros orais.

Os relatos aqui apresentados são apenas para chamar a atenção de pesquisadores para problemas a resolver para uma pesquisa sobre categorias de texto, mas também e, sobretudo, para dizer que, como pesquisadores, temos que estender a pesquisa aos gêneros que não são "públicos", no sentido de os tornar disponíveis, independentemente de sermos ou não da comunidade. $\mathrm{O}$ não estender o estudo para outras comunidades levará tanto a termos uma pesquisa tipológica restrita, focada apenas em alguns gêneros que serão cada vez mais 
explorados, quanto a não percebermos fatos e fenômenos do funcionamento da língua em textos. Foi a observação de um número superior a 600 gêneros, em nossas pesquisas, de nossos alunos e orientandos e nos trabalhos dos colegas pesquisadores, que tivemos o prazer de ler, o que nos levou a perceber que as diferentes categorias de texto não eram todas da mesma natureza e a propor os tipelementos, para evitar que nos estudos se confundam elementos diferentes, julgando ter que dar a eles o mesmo tratamento teórico, empírico, na descrição de sua constituição e funcionamento. Muitos podem não concordar com a proposta feita, muitos vão achá-la pertinente, mas ninguém pode afirmar que uma visão geral dos fatos não seja necessária antes de nos aprofundarmos em pontos específicos, sob pena de se chegar a conclusões e generalizaçóes equivocadas. É essa consciência que nos leva a falar do próximo tópico.

\section{A horizontalização e a verticalização na pesquisa}

Em Travaglia (2008), falamos da necessidade de desenvolver as pesquisas linguísticas com duas posturas diferentes, que denominamos de horizontalização e verticalização na pesquisa. Afirmamos, então, que:

Temos horizontalização quando observando um fato ou fenômeno, no nosso caso, um fato ou fenômeno linguístico, trabalhamos buscando uma visão mais ampla, abrangente de tudo o que possa estar envolvido neste fato ou fenômeno e consequentemente que pode ser objeto de estudo ao tratarmos do mesmo. Como que se constitui, assim, um campo de estudo. Muitas vezes a horizontalização demanda uma descrição menos detalhada, pelo menos em alguns aspectos ou estágios da pesquisa. A horizontalização exige, comumente, um corpus mais amplo. Temos a verticalização quando trabalhamos observando um desses aspectos envolvidos em dado fato ou fenômeno, ou seja, tomamos um ponto mais específico e aprofundamos o estudo do mesmo em detalhes ou sob uma perspectiva configurada por modelos ou teorias lingüísticas ou por disciplinas linguísticas. A verticalização pode ou não exigir um corpus mais ou menos amplo dependendo do fato ou aspecto que se estuda. Os conceitos de horizontalização e verticalização não são absolutos, pois, como veremos, um estudo pode ser uma abordagem horizontal de um fato ou aspecto deste fato, mas 
ser uma verticalização se considerarmos outro fato ou fenômeno como o objeto de pesquisa.

As duas formas de estudo são necessárias, pois sem a horizontalização corremos o risco de, por não se ter um quadro geral, em que determinado fato ou fenômeno ou aspecto destes se encaixa, terminarmos por tirar conclusões, fazer generalizações e afirmaçōes que não se sustentam, quando o fato ou aspecto estudado é confrontado com outros que se lhe avizinham ou são com ele correlacionados em algum sentido (TRAVAGLIA, 2008, p. 213, 214).

Nos estudos tipológicos dos textos, essas duas posturas são necessárias. A horizontalização vai ser representada pela construção de uma teoria tipológica geral, que pode ser nos termos que aqui referimos e que propusemos em outros textos, isso porque vai nos permitir encaixar fenômenos específicos em um quadro mais geral. Assim, ao falarmos em gênero, estaremos distinguindo a categoria de uma dada natureza das de outras naturezas: tipo, subtipo, espécie e não vamos tratar tudo como sendo uma só coisa, o que nos impediria de ver, por exemplo, as relaçóes existentes entre as categorias de texto de diferentes naturezas e a cometer equívocos em sua caracterização. Também representa uma horizontalização na pesquisa tipológica de textos o levantamento de todos os gêneros de uma comunidade discursiva, as relações gerais e básicas entre eles e sua caracterização em termos gerais, utilizando os cinco parâmetros especificados anteriormente. Esse tipo de pesquisa tem estado pouco presente nos estudos linguísticos do Brasil, talvez devido às dificuldades de busca nas comunidades a que nos referimos no item 3, mas também porque, na academia, inclusive nos programas de pós-graduação, talvez ainda não se veja esse tipo de pesquisa como algo que possa ser objeto de uma dissertação ou tese. Seria sempre necessário algo mais para se tornar uma tese ou dissertação. Exemplos de trabalhos desse tipo são os de Pimenta (2007), na parte em que levanta e caracteriza 130 gêneros presentes nos processos penais, da comunidade forense; e o trabalho de Silva (2007), na parte em que levanta e caracteriza 12 gêneros jornalísticos, distinguindo-os de outros 20 que aparecem nos jornais e revistas, mas não seriam jornalísticos, e sim de outras comunidades que usam os jornais e revistas como veículo, serviço, suporte. Assim, o que se tem observado mais na pesquisa sobre tipologia é a centração das pesquisas, estudos e trabalhos sobre gênero apenas em um pequeno número de gêneros. A significação social desses gêneros não 
justifica essa centração. Parece-nos que ela advém primeiro da facilidade de acesso aos gêneros e, segundo, de uma razão menos perceptível, mas provavelmente a mais forte, que é uma perspectiva da pesquisa no Brasil que não valoriza pesquisas do tipo levantamento, sondagem ou survey, valorizando mais os estudos monográficos ou de profundidade. ${ }^{12}$

A verdade é que nos estudos tipológicos no Brasil, nos parece, a horizontalização tem sido pouco praticada, criando os problemas aludidos, por falta de inserção dos estudos em quadros mais gerais que minimizam certos tipos de equívoco nas conclusões e generalizações, sem as quais as pesquisas perdem seu valor.

O que estamos propondo é que, para um melhor desenvolvimento da pesquisa sobre tipologia de textos, é importante e fundamental haver uma teoria tipológica mais geral e um levantamento mais amplo das categorias de texto, principalmente dos gêneros, mas também dos demais tipelementos existentes na sociedade e cultura brasileiras agrupados por comunidades discursivas e esferas de ação social. Isso permitiria o enquadramento das categorias em aspectos diversos e forçaria o olhar para o trabalho com gêneros que não têm caído nas graças dos pesquisadores.

A verticalização ocorre na pesquisa tipológica quando o estudo propõe tarefas como:

a) a caracterização detalhada e profunda de uma categoria de textos, seja tipo, subtipo, gênero ou espécie, como a caracterização do gênero acórdão jurídico feita por Lellis (2008) em sua tese ou por Silva (2007) quando busca mostrar as várias faces com que a notícia pode se apresentar, aprofundando, assim, sua caracterização. Também Nepomuceno (2005) fez um estudo desse tipo, ao caracterizar o gênero tira, bem como Ferreira (2005), ao buscar a caracterização da crônica;

b) a caracterização de um gênero e sua diferenciação ou levantamento de particularidades em diferentes comunidades discursivas, por exemplo, verificar se o convite, um gênero usado em quase todas as comunidades discursivas, apresenta alguma(s) particularidade(s) em uma delas em confronto com as demais. $\mathrm{O}$ mesmo ponto se pode verificar quanto ao plano de curso da área de ação social educacional, para a educação formal quando ela acontece em diferentes comunidades que realizam educação formal de algum tipo (escolas de diferentes níveis, indústria, 
comércio, grupos religiosos, etc.) $;^{13}$

c) a verificação de que particularidades um gênero apresenta em suas diferentes espécies. Por exemplo, se o atestado além da particularidade do gênero apresenta outras particularidades, conforme seja um atestado de saúde ou médico, de bons antecedentes, de idoneidade moral, de frequência em cursos, etc.

d) verificar como acontece um dado aspecto (por exemplo a argumentação) em um certo gênero, como o estudo feito por Parreira $(2006,2008)$ em que se explicita como os operadores argumentativos e os tipos de argumentos configuram a argumentação nos editoriais de jornal ou o estudo feito por Melo (2005), que verifica como trechos descritivos, narrativos e injuntivos são utilizados argumentativamente nos editoriais de jornal, um gênero necessariamente dissertativo e argumentativo com esses dois tipos dominantes e em fusão. Aqui também se incluiria o trabalho de Andrade (2010), que pesquisa o uso da modalidade na construção do artigo científico;

e) a distinção de gêneros muito próximos, ou com grande número de características comuns, por exemplo, mitos e lendas; ensaios e artigos científicos; apólogos, fábulas e parábolas. A distinção desses três últimos gêneros entre si, apesar do grande número de características comuns, é justamente o tema da pesquisa de Arantes $(2006,2008)$ que aponta as características pelas quais eles se distinguiriam;

f) a evolução de um gênero em outro, como é o caso da carta e dos muitos gêneros dela derivados, conforme indica Bazerman (2005, cap. 4);

g) a mudança de um gênero de uma época para outra. Esse é um estudo diacrônico que, até onde sabemos, não foi feito para gêneros da sociedade e cultura brasileiras. Ferreira (2005) observa as crônicas desde seu surgimento nos jornais, até o momento de seu estudo, mas não registra uma evolução de caracteres do gênero. Apenas chama a atenção para a preferência de dominância da narrativa ou da dissertação na constituição do gênero em diferentes épocas;

h) a interrelação dos mais diferentes modos entre gêneros diversos de uma comunidade discursiva ou de diversas comunidades. Assim, por exemplo, um estudo de como as leis e regulamentações de modo geral geram uma série de gêneros em muitas comunidades. Veja-se o 
exemplo dos gêneros da comunidade educacional a que nos referimos no item 2. Outro caso dessa inter-relação é a espécie de intertextualidade a que nos referimos também no item 2 ao falar do formulário do imposto de renda. Um bom exemplo dessas inter-relações é o apresentado por Pimenta (2007), ao verificar quais gêneros entre os presentes nos processos penais mais influenciam a sentença dada pelo juiz. Este é, sem dúvida, um caso das relações entre gêneros no seu funcionamento social e que pode ser de interesse dos agentes da justiça, sobretudo advogados e promotores;

i) verificação do funcionamento discursivo e social das categorias propostas. Sobretudo como um gênero é usado na ação social e como é a rede social que interliga gêneros entre si. É o que fez Pimenta (2007), ao verificar que gêneros influenciavam a construção das sentenças;

j) etc.

Outros aspectos podem ser objeto de verticalização, por isso não fechamos essa enumeração de aspectos que podem ser abordados.

Não incluímos aqui os estudos sobre ensino de categorias de texto, tão frequentes em nossa atualidade, sobretudo depois que os Parâmetros Curriculares Nacionais, surgidos em 1998, propuseram os gêneros como o centro do ensino de Língua Portuguesa nos Ensinos Fundamental e Médio. Na maioria dos casos, eles não desenvolvem teorias nem contribuem para a descrição da constituição e funcionamento das categorias de texto, mas as utilizam buscando verificar o que o ensino deve focalizar e como poderia ou até mesmo deveria ser o ensino. Assim sendo, embora sejam uma pesquisa que envolva tipologia, não seriam propriamente pesquisas para desenvolver aspectos teóricos que é o que nos interessa mais diretamente aqui.

\section{A questão terminológica}

A terminologia utilizada não influencia propriamente a pesquisa que está sendo desenvolvida, até porque, para aquele que faz o estudo, os termos utilizados têm, ou pelo menos deveriam ter, um sentido específico e bem definido; todavia, creio que a terminologia é importante para a comunicação entre os pesquisadores.

O que mais traz dificuldades é o fato de os mesmos termos serem utilizados para conceitos diversos, que são totalmente diferentes ou que às vezes 
se superpõem em parte. Assim, por exemplo, Bazerman (2005) utiliza os termos tipo, gênero e espécie de modo mais ou menos livre e geral, correspondendo, nos parece, ao que Travaglia chama de categorias de texto. O termo "gêneros discursivos ou de texto" utilizado por Bakhtin (1992) também corresponde, em nossa leitura, ao que Travaglia chama de categorias de texto. Salvo equívoco de nossa parte, o termo "gêneros" da teoria literária não corresponde ao que a Linguística chama de gêneros, mas ao que ela chama de tipos.

Às vezes, temos termos diferentes para um mesmo conceito ou conceitos muito próximos. Assim, parece-nos que o termo "sequência", utilizado por Adam, equivale ao termo "tipo", tal como definido por Travaglia. As categorias que a Teoria Literária designou como gêneros são para Travaglia ([2003]/2007) tipos e o que ela chama de espécies ora correspondem ao que Travaglia chama de espécies, ora ao que chama de gêneros, dependendo da caracterização dada. Assim, a Teoria Literária teria reunido em um mesmo compartimento coisas de naturezas distintas.

Enfim, o que nos parece importante, já que uma uniformização terminológica parece pouco provável, é que o pesquisador não considere que o termo é autodefinido e sempre deixe explícito e de modo o mais preciso possível o que cada termo identifica para ele.

Não nos alongaremos aqui sobre a questão terminológica.

\section{Considerações finais}

Em face do que dissemos aqui, acreditamos que o pesquisador, ao se dedicar à pesquisa sobre tipologogia textual na perspectiva da Linguística Textual, tem de se propor às seguintes tarefas e cuidados para maior qualidade da pesquisa:

a) propor ou adotar uma teoria tipológica geral de textos que permita inserir em quadro mais amplo os estudos realizados, evitando equívocos desnecessários. Estamos considerando uma teoria para os estudos linguísticos, já que outras áreas interessadas na questão tipológica dos textos podem constituir outras teorias que muito provavelmente serão constituídas com elementos muito próximos do que explicitamos aqui;

b) estabelecer metodologias para fazer a identificação e o levantamento das categorias de texto, superando dificuldades diversas, encontradas 
no trabalho efetivo com as comunidades discursivas e áreas de ação social em que as categorias de texto se constituem e funcionam;

c) definir parâmetros e critérios para a caracterização das categorias de texto, ${ }^{14}$ não só utilizando o que já foi estabelecido por outros, mas buscando parâmetros e critérios outros que possam ser utilizados e que podem surgir na ampliação do campo empírico de observação, proposto quando falamos de horizontalização;

d) deixar claro o aspecto tipológico que está sendo pesquisado e como ele se insere em um quadro mais geral;

e) tratar com seriedade a metalinguagem, fixando uma terminologia claramente definida, sem pressupor que todos os que terão contato com o estudo tenham um mesmo conceito para o termo.

Cremos que a observação dos pontos para os quais chamamos a atenção aqui pode fazer a pesquisa sobre tipologia textual ganhar em qualidade e também em abrangência. Evidentemente outros aspectos igualmente pertinentes podem surgir com a evolução das pesquisas e a consideração desses aspectos certamente será importante para a qualidade das pesquisas sobre tipologia textual. É preciso, pois, estar atento a tais aspectos, ao desenvolver estudos nesta área. Finalizamos, lembrando que as consideraçôes aqui feitas para os estudos de tipologia textual, na área da Linguística Textual, com certeza se aplicam de modo geral a outras pesquisas linguísticas nos mais diferentes campos de estudo da Linguística.

\section{Notas}

${ }^{1}$ Em nossa interpretação, o termo gêneros discursivos ou de texto usado por Bakhtin (1992) corresponde ao que chamamos aqui de categorias de texto, uma vez que em seus estudos Bakhtin inclui entre os gêneros categorias que aqui vamos considerar tipo, enquanto um dos tipelementos.

${ }^{2}$ Em Travaglia (2004) e outros textos, usamos o termo "elemento tipológico" para designar o que agora designamos por "categoria de texto". Mudamos o termo por considerar "categoria de texto", mais claro e direto para identificar o conceito.

${ }^{3}$ A caracterização de várias dessas tipologias pode ser vista em Travaglia ([2003]/2007).

${ }^{4}$ Sobre os subtipos, veja Travaglia (2009).

${ }^{5}$ Ver MELO (2005). 
${ }^{6}$ Fávero e Koch (1983, p. 14) afirmam que uma das tarefas da Linguística Textual é "diferenciar as várias espécies de textos".

${ }^{7}$ O texto original é de 1996, tendo sido publicado na revista Enjeux, 37-38.

${ }^{8}$ Exemplo tomado a Bazerman (2005, capítulo 3) e adaptado aos objetivos pretendidos aqui.

${ }^{9}$ É relativamente frequente termos grupos de gêneros com um objetivo e função sociocomunicativa comum. É o caso, por exemplo, também dos gêneros atestado, certidão, certificado, declaração, que têm como objetivo comum "dar fé da verdade de algo" ou dos gêneros petição, memorial, requerimento, abaixo assinado, requisição, solicitação, que têm o objetivo comum de "fazer pedido ou solicitação" (cf. TRAVAGLIA, 2002, p. 152).

${ }^{10}$ Parece-nos que as principais teorias tipológicas em circulação na academia brasileira se preocuparam sempre em estabelecer e distinguir categorias de texto da natureza dos tipos (às vezes propondo como tipos o que seriam subtipos), o que seria uma limitação. Estão, nesse caso, todas as que citamos anteriormente neste texto (propostas por Vanoye, Benveniste, Simonin-Grumbach, Weinrich, Werlich, Fávero e Koch, Adam, Bronckart, Dolz e Schneuwly e a Teoria Literária), para evidenciar que não poderiam ser reunidas em um único esquema classificatório. Além disso, há muito empenho em definir o que seria gênero e listar alguns exemplos. Mesmo com toda essa definição de gênero, em dados momentos, parece difícil definir se algo é ou não um gênero. Assim, por exemplo, o e-mail é apresentado por muitos como um gênero novo surgido em função de novas tecnologias, parece-nos mais um serviço (como o correio tradicional), já que um e-mail pode conter gêneros diversos: um convite, cartões de cumprimentos, por razões diversas (aniversários, formaturas, núpcias, Natal, Páscoa, etc.), uma declaração, um poema, uma convocação, correspondências diversas (como cartas, circulares, ofícios, memorandos, etc.), etc. A pesquisa precisa estabelecer critérios para dizer que algo é inequivocamente um gênero, pois percebe-se que em certos momentos se chama de gênero elementos que se pode discutir muito facilmente que não o seriam.

${ }^{11}$ Ver SILVA (2007, p. 68).

${ }^{12}$ Ver MARCONI e LAKATOS (2006, p. 22).

${ }^{13}$ Ver, em TRAVAGLIA (2011), sobre o gênero "programa padrão de instrução (PPI)" 
que aparece na comunidade militar (exército) e é um plano de curso.

${ }^{14}$ Ver Travaglia (2007a).

\section{Bibliografia}

ADAM, Jean Michel. Les textes: types et prototypes - Récit, description, argumentation, explication et dialogue. Paris: Nathan, 1993.

ANDRADE, Valdete Aparecida Borges. Modalização em artigos científicos na área de Linguística. 2010. 150f. Dissertação (Mestrado em Estudos Linguísticos) - ILEEL/ Universidade Federal de Uberlândia, 2010.

ARANTES, Marilza Borges. A argumentação nos gêneros fábula, parábola e apólogo. 2006. 170f. Dissertação (Mestrado em Lingüística) - ILEEL/Universidade Federal de Uberlândia, 2006.

ARANTES, Marilza Borges. Apólogos, fábulas e parábolas: confluências e divergências. In: TRAVAGLIA, Luiz Carlos; FINOTTI, Luisa Helena Borges; MESQUITA, Elisete Maria Carvalho de (Org.). Gêneros de texto: caracterização e ensino. Uberlândia: EDUFU, 2008.

BAKHTIN, Mikhail. Estética da criação verbal. São Paulo: Martins Fontes, 1992.

BAZERMAN, Charles. Gêneros textuais, tipificação e interação. Organizado por Ângela Paiva Dionísio e Judith Chambliss Hoffnagel. Traduzido e adaptado por Judith Chambliss Hoffnagel. São Paulo: Cortez, 2005.

BRONCKART, Jean-Paul. Atividades de linguagem, textos e discursos - Por um interacionismo sócio-discursivo. São Paulo: EDUC, 2003

CARDOSO, Solange A. Faria. O diário-de-obras no sistema de gêneros da Engenharia Civil.: Revista SELL: Simpósio Internacional de Estudos Línguísticos e Literários da UFTM, v. 2, n. 2, 2010, Uberaba, 16 p. Disponível em: <http:// www.uftm.edu.br/revistaeletronica/index.php/sell/article/view/33>. Acesso em: 16 jul. 2012.

DOLZ, Joaquim; SCHNEUWLY, Bernard e colaboradores. Gêneros e progressão em expressão oral e escrita - Elementos para reflexões sobre uma experiência suíça (francófona). In: DOLZ, Joaquim; SCHNEUWLY, Bernard. Gêneros orais e escritos na escola. Tradução e organização de Roxane Rojo e Glaís Sales Cordeiro. Campinas, SP: Mercado de Letras, 2004.

FÁVERO, Leonor Lopes; KOCH, Ingedore G. V. Linguística textual: introdução. São Paulo: Cortez, 1983. 
FÁVERO, Leonor Lopes; KOCH, Ingedore G. V. Contribuição a uma tipologia textual. Letras \& Letras, Uberlândia, Departamento de Letras/UFU, v. 3, n. 1, p.3-10, jun. 1987.

FERREIRA, Simone Cristina Salviano. A crônica: problemáticas em torno de um gênero. 2005. 207f. Dissertação (Mestrado em Lingüística) - Universidade Federal de Uberlândia, 2005.

GUIMARÃES, Eduardo. Os limites do sentido. Campinas, SP: Pontes, 1995.

LELLIS, Lélio Maximino. O texto nos acórdãos dos tribunais. 2008. 295f. Tese (Doutorado em Língua Portuguesa) - Pontifícia Universidade Católica de São Paulo, 2008.

MARCONI, Marina de Andrade; LAKATOS, Eva Maria. Técnicas de pesquisa: planejamento e execução de pesquisas, amostragens e técnicas de pesquisa, elaboração, análise e interpretação de dados. São Paulo: Atlas, 2006.

MARCUSCHI, Luiz Antônio. Gêneros textuais: definição e funcionalidade. In: DIONÍSIO, Ângela Paiva; MACHADO, Anna Rachel; BEZERRA, Maria Auxiliadora (Org.). Gêneros textuais e ensino. Rio de Janeiro, Lucerna, 2002. p. 19-36.

MELO, Carolina Santos. Tipos de textos empregados com função de argumento na dissertação argumentativa. 2005. 177f. Dissertação (Mestrado em Lingüística) ILEEL/Universidade Federal de Uberlândia, 2005.

NEPOMUCENO, Terezinha. Sob a ótica dos quadrinhos: uma proposta textualdiscursiva para o gênero tira. 2005. 143f. Dissertação (Mestrado em Lingüística) Universidade Federal de Uberlândia, 2005.

PARREIRA, Míriam Silveira. Um estudo do uso de operadores argumentativos no gênero editorial de jornal. 2006. 223f. Dissertação (Mestrado em Lingüística) Universidade Federal de Uberlândia/ ILEEL, 2006.

PARREIRA, Míriam Silveira. Operadores argumentativos e técnicas de argumentação em editoriais de jornal. In: TRAVAGLIA, Luiz Carlos; FINOTTI, Luisa Helena Borges; MESQUITA, Elisete Maria Carvalho de (Org.). Gêneros de texto: caracterização e ensino. Uberlândia: EDUFU, 2008.

PIMENTA, Viviane Raposo. Textos forenses: um estudo de seus gêneros textuais e sua relevância para o gênero "sentença". 2007. 192 + 237f. Dissertação (Mestrado em Lingüística) - ILEEL / Universidade Federal de Uberlândia, 2007.

SILVA, Pollyanna Honorata. Os gêneros jornalisticos e as várias faces da notícia. 2007. 225 f. Dissertação (Mestrado em Linguística) - ILEEL/Universidade Federal de Uberlândia, 2007. 
SIMONIN-GRUMBACH, Jenny. Para uma tipologia dos discursos. In: Lingua, Discurso, Sociedade. São Paulo: Global, 1983.

TRAVAGLIA, Luiz Carlos. Da distinção entre tipos, gêneros e subtipos de textos. Estudos Lingüisticos, Marília, SP, n. XXX, Revista em CD-ROM, Artigo 200, 6 p. Grupo de Estudos Lingüísticos do Estado de São Paulo / Fundação de Ensino "Eurípedes Soares da Rocha, 2001. Disponível em: <www.ileel.ufu.br/travaglia>.

TRAVAGLIA, Luiz Carlos. Gêneros de texto definidos por atos de fala. In: ZANDWAIS, Ana (Org.). Relaçôes entre pragmática e enunciação. Porto Alegre: Sagra Luzzato, 2002. p. 129-153. (Coleção Ensaios - no17) Disponível em: $<$ www.ileel.ufu.br/travaglia>.

TRAVAGLIA, Luiz Carlos. Tipologias textuais literárias e lingüísticas. SCRIPTA, Belo Horizonte: CESPUC / Editora PUC-MG, v. 7, n. 14, p. 146-158, 2004. Disponível em: <www.ileel.ufu.br/travaglia>.

TRAVAGLIA, Luiz Carlos. Tipelementos e a construção de uma teoria tipológica geral de textos. In: FÁVERO, Leonor Lopes; BASTOS, Neusa M. de O. Barbosa; MARQUESI, Sueli Cristina (Org.). Lingua Portuguesa pesquisa e ensino. V. II. São Paulo: EDUC/FAPESP, 2007. p. 97-117. Disponível em: <www.ileel.ufu.br/travaglia>.

TRAVAGLIA, Luiz Carlos. A caracterização de categorias de texto: tipos, gêneros e espécies. $A L F A$, São Paulo, v. 51 n. 1, p. 39-79. 2007a. Disponível em: <http:// www.alfa.ibilce.unesp.br/download/v51-1/03-Travaglia.pdf>.

TRAVAGLIA, Luiz Carlos. Das relações possíveis entre tipos na composição de gêneros. SIMPÓSIO INTERNACIONAL DE ESTUDOS DE GÊNEROS TEXTUAIS, 4º, organizadores: Adair Bonini, Débora de Carvalho Figueiredo, Fábio José Rauen. Anais... Tubarão: UNISUL, 2007b. p. 1297-1306. Disponível em: <www.ileel.ufu.br/ travaglia>.

TRAVAGLIA, Luiz Carlos. Horizontalização e verticalização na pesquisa linguística - dois casos: a classificação e a caracterização de textos e a gramaticalização de verbos. Desenredo - Revista do Programa de Pós-Graduação em Letras da Universidade de Passo Fundo, UPF, v. 4, n.2, p. 212-240, jul./dez. 2008. ISSN 1808-656X. Disponível em: <www.ileel.ufu.br/travaglia>.

TRAVAGLIA, Luiz Carlos. Sobre a possível existência de subtipos. CONGRESSO INTERNACIONAL DA ABRALIN, VI, organizador: Dermeval da Hora. Anais... v. 2, n. 2. João Pessoa: ABRALIN/ UFPB, 2009. p. 2632-2641. Disponível em: $<$ www.ileel.ufu.br/travaglia>.

TRAVAGLIA, Luiz Carlos. Alguns gêneros militares. SIMPÓSIO NACIONAL, XIII / INTERNACIONAL DE LETRAS E LINGUÍSTICA, III. Anais... Uberlândia: 
EDUFU, 2011. 14 p. ISSN: 2237-6607. Disponível em: <http://www.ileel.ufu.br/ anaisdosilel/pt/default.asp; www.ileel.ufu.br/travaglia> .

TRAVAGLIA, Luiz Carlos. Esferas de ação social e comunidades discursivas: conceitos superpostos, mas distintos. In: BASTOS, Neusa Barbosa (Org.). Lingua Portuguesa: aspectos linguísticos, culturais e identitários. São Paulo: EDUC, 2012. p. 75-90.

VANOYE, Francis. Usos da linguagem - problemas e técnicas na produção oral e escrita. Tradução e adaptação de Clarisse Madureira Sabóia et al. São Paulo: Martins Fontes, 1982.

WEINRICH, Harald. Estructura y función de los tiempos en el lenguaje. Madrid: Gredos, 1968

WERLICH, E. Typologie der texte. Heidelberg: Quelle \& Meyer, 1975. 